\title{
DAS VOLLE SUBJEKT. DOMINACIÓN, MORALIDAD Y LIBERTAD EN EL PENSAMIENTO DE T. W. ADORNO
}

Agustín Mendez 


\title{
DAS VOLLE SUBJEKT. DOMINACIÓN, MORALIDAD Y LIBERTAD EN EL PENSAMIENTO DE T. W. ADORNO*
}

\begin{abstract}
Resumen: Desde Dialéctica de la llustración hasta Dialéctica negativa, el materialismo filosófico llevado adelante por T. W. Adorno ha ubicado en un lugar central de sus reflexiones la problemática de lo corporal, poniéndolo en discusión directa tanto con el psicoanálisis y su teoría de las pulsiones, así como con las diferentes versiones del idealismo. La reflexión acerca de este ámbito, permitirá exponer tanto el carácter represivo de la sociedad; también, la posibilidad de una ética verdaderamente democrática.
\end{abstract}

Palabras Clave: Cuerpo, dominación, moralidad, libertad, intersubjetividad.

\section{DAS VOLLE SUBJEKT. DOMINATION, MORALITY AND FREEDOM IN THE THOUGHT OF T. W. ADORNO}

\begin{abstract}
From Dialectic of Enlightenment until Negative dialectics, the philosophical materialism led forward by T. W. Adorno has been located in a central place of its reflections, the problematic of the body, putting it in direct discussion with both psychoanalysis and his theory of the impulses as well as with the different versions of idealism. The reflection about this area, will allow you to expose both the repressive nature of society as well as the possibility of a truly democratic ethics.
\end{abstract}

Keywords: Body-domination-morality-freedom-intersubjetivity

Fecha de recepción: mayo 13 de 2014

Fecha de aceptación: septiembre 9 de 2014

Forma de citar: Mendez, A. (2015). "Das volle subjekt. Dominación, moralidad y libertad en el pensamiento de T. W. Adorno". Revista Filosofía UIS. 14 (1). pp. 137-168.

Agustín Mendez: argentino. Licenciado en Ciencia política, Universidad de Buenos Aires. Investigador y Profesor de la materia "Psicoanálisis y Ciencias Sociales" y del seminario de investigación "Discurso, política y sujeto", FSOC-UBA.

Correo electrónico: a_mendez86@hotmail.com

\footnotetext{
* Artículo de reflexión.
} 


\section{DAS VOLLE SUBJEKT. DOMINACIÓN, MORALIDAD Y LIBERTAD EN EL PENSAMIENTO DE T. W. ADORNO}

\section{Dialéctica del iluminismo: constitución del sí mismo y represión de los instintos}

Es bien sabido que T. W. Adorno, en su obra escrita con M. Horkheimer, Dialéctica de la llustración, realizó una crítica corrosiva a la reducción del ideal ilustrado a un simple proyecto de dominación y poder, donde se persigue, como único objetivo "liberar a los hombres del miedo y constituirlos en señores" (Adorno y Horkheimer, 2001, p. 59). De acuerdo con la afirmación reproducida, la clave será entender qué significa volver a los hombres "señores" y qué mecanismos se ponen en juego para alcanzar tal cometido.

Según su lectura ${ }^{1}$, la Ilustración despliega un programa cuyo locus principal está basado en el dominio de la naturaleza, eliminando el paradigma animista que antiguamente determinaba su concepción. Ya no aparece regida por deidades trascendentes que la doten de una vivacidad propia; por el contrario, se ha convertido en un sustrato descualificado disponible para la utilización del hombre. Esta situación responde al cariz específico que adopta la racionalidad: ser el vehículo de la autoconservación. El hombre, en tanto posee una existencia corporal, forma parte de la naturaleza; sin embargo, para lograr dominarla, debe diferenciarse de ella, negando su componente sensible. La hipostatización de dicha separación es el gesto por el cual se eleva al sujeto como fuente autónoma de sentido.

\footnotetext{
${ }^{1}$ Es necesario dejar planteado desde el inicio que este trabajo se encuadra, en un contexto general, dentro de las lecturas realizadas, principalmente, por Bernstein (2001), Cabot (1997), Foster (2007), Jarvis (1998), Maiso (2010), O'Connor (2004), Tafalla (2003), Zamora (2004) y Zuidervaart (2007).
} 
Como se puede notar, Adorno y Horkheimer despliegan su análisis basándose en el reconocimiento de una afinidad mimética originaria entre el hombre y su entorno, donde aquel se asimila a este para lograr conocerlo ${ }^{2}$. No obstante, el sujeto, al devenir su "señor", debe rechazar este momento de entrega y descentramiento ya que pone en jaque la distancia necesaria sobre la que se asienta la aprehensión de la naturaleza. El precio que se paga por la pérdida de esta dimensión es la mutilación de la experiencia. De esta forma,

el dominio universal sobre la naturaleza se vuelve contra el mismo sujeto pensante, del cual no queda más que aquel «yo pienso» eternamente igual, que debe poder acompañar todas mis representaciones. Sujeto y objeto quedan, ambos, anulados. El sí mismo abstracto, el derecho a registrar y sistematizar, no tiene frente a sí más que el material abstracto, que no posee ninguna otra propiedad que la de ser substrato para semejante posesión (80).

Por consiguiente, la Ilustración se empeña en eliminar aquello que escapa a su lógica de conocimiento, ya que lo distinto, en tanto no conocido, se torna amenazante y peligroso. En virtud de ello, encontrará en la abstracción ese elemento que permite pasar por el rasero de lo igual a lo diverso: el desprecio por la especificidad del objeto, hace que este sea únicamente concebido a partir de la proyección de categorías subjetivas. Sin embargo, el corolario de este proceder es que no solo el objeto se encuentra sustraído de sus rasgos particulares, sino que también el sujeto lo está de su individualidad, deviniendo una cáscara vacía, sin ningún tipo de determinación singular. En definitiva, para lograr erigirse como una identidad diferenciada del medio ambiente, de la cual en última instancia procede, la figura del hombre termina por conformar un "yo abstracto", des-diferenciado.

Ahora bien, este modo de tratar la naturaleza externa es replicada con respecto a la naturaleza interna del sujeto: su multiplicidad sensorial debe ser negada y supeditada a los requerimientos del entendimiento objetivante. Sus deseos, necesidades e instintos deben ser sometidos en pos de su autoconservación, encauzando su energía hacia el dominio de la naturaleza y el trabajo productivo; los demás impulsos deberán ser reprimidos. Dominar es dominarse, de allí que Adorno y Horkheimer sostengan que "por debajo de la historia conocida de Europa corre una historia subterránea. Es la historia de la suerte de los instintos y las pasiones humanas reprimidos o desfigurados por la civilización" (277).

\footnotetext{
${ }^{2}$ La noción de mímesis utilizada por Adorno tiene diversas definiciones. Un recorrido muy completo por los múltiples sentidos empleados puede encontrarse en Jay, 1997, pp. 31-33. A su vez, para el estudio comparativo entre la lectura adorniana y benjaminiana de dicha noción remito a Gagnebin, 1993, pp. 63-86.
} 
Al seguir esta idea, la historia deviene en una urdiembre de dominaciones, tanto de la naturaleza externa como interna del hombre, así como la que ejercen los individuos entre sí: "el despertar del sujeto se paga con el reconocimiento del poder en cuanto principio de todas las relaciones" (64). Cabe precisar que en esta clave se debe entender la apelación al poema homérico, leído bajo el concepto benjaminiano de alegoría 3 , como el proceso mediante el cual se consuma "el itinerario del sí mismo —infinitamente débil en el cuerpo frente al poder de la naturaleza y sólo en estado de formación en cuanto autoconciencia- a través de los mitos" (100).

La tesis fundamental del excurso sobre Odiseo es interpretar su figura como la del prototipo del primer burgués, dado que en su peripecia se refleja de modo prístino el destino de sometimiento de lo corporal como mecanismo fundamental del ordenamiento social. La escisión entre cuerpo y alma, entre res extensa y res cogita, la cual fundamenta la victoriosa travesía del rey de Ítaca, es el nervio central de la reproducción del sistema capitalista: "desde que el trabajo espiritual se separó del corporal bajo el signo del dominio del espíritu, de la justificación del privilegio, el espíritu separado tuvo que vindicar con la exageración de la mala conciencia precisamente esa pretensión de dominio que él deduce de la tesis de que él es lo primero y originario y por tanto olvidar de donde procede su pretensión, so pena de derrumbarse" (Adorno, 2008, p. 169).

De este modo, la astucia, el engaño y el sacrifico, elementos a los que apela el héroe homérico para enfrentar las vicisitudes de su viaje, son los mismos que están en la base de las estructuras de dominación que fundamentan el proyecto ilustrado:

Con la negación de la naturaleza en el hombre se hace confuso y oscuro no sólo el telos del dominio de la naturaleza exterior, sino también el de la propia vida. En el momento en que el hombre se amputa la conciencia de sí mismo como naturaleza, todos los fines por los que se mantiene en vida: el progreso social, el incremento de todas las fuerzas materiales e intelectuales, incluso la conciencia misma, pierden todo valor, y la entronización del medio como fin, que adquiere en el capitalismo tardío el carácter de abierta locura, es perceptible ya en la prehistoria de la subjetividad (Adorno y Horkheimer, 2001, pp. 106-107).

A través del análisis de los distintos obstáculos a los que debe sobreponerse Odiseo, se percibe que el camino hacia la consolidación de una identidad autoconsciente se realiza mediante la negación de la dimensión somática del individuo, de ahí que "la historia de la civilización es la historia de la introyección del sacrificio. En otras palabras: la historia de la renuncia" (100). Esta última

\footnotetext{
${ }^{3}$ Para la utilización y recepción del concepto benjaminiano de alegoría, dentro del contexto de Dialéctica de la llustración, véase Foster, 2007, pp. 57-87 y Gómez, 1998, pp. 25-43.
} 
afirmación señala la paradoja en la que se encuentra anclada la construcción de una subjetividad totalmente espiritualizada: en el mismo gesto por el cual se afirma como una identidad pura e igual a sí, se niega su singularidad y especificidad, si se atiende al hecho de que "la identidad del sí-mismo y de la autoalienación se acompañan mutuamente desde el comienzo" (Adorno, 2008, p. 204). La supervivencia de Odiseo trae consigo el precio de la reificación del sujeto al perder su relación mimética con el mundo, siendo ahora preservada la mímesis en el sentido pervertido de un sí mismo objetivado que imita un entorno desprovisto de significación propia, como se ilustra en seguida: "la ratio que reprime a la mímesis no es sólo su contrario. Ella misma es mímesis: mímesis de lo muerto. El espíritu subjetivo, que disuelve la animación de la naturaleza, sólo domina a la naturaleza «desanimada» imitando su rigidez y disolviéndose él mismo en cuanto animado" (Adorno y Horkheimer, 2001, p. 109).

Este mecanismo, por el cual se perpetran en el mismo gesto, afirmación y disolución del sujeto, constituye un momento central para desentrañar el modo de estructuración y reproducción del todo social, volviendo al cuerpo un mero instrumento de trabajo, al negarle su vinculación con toda forma de placer y goce. Uno de los pasajes donde se expresa con mayor claridad dicha negación es en la lectura adorniana del canto de las sirenas: Odiseo, que solo concibe posible escuchar el canto de estos seres si se hace atar al mástil del navío para evitar caer rendido a su hechizo, convierte a su cuerpo, en pos de su preservación, en un bien más de los que integran la tripulación. A su vez, obliga a los remeros de su embarcación a taparse los oídos, volviéndolos, de esta manera, prácticos y laboriosos, a partir de la negación de toda forma de disfrute. La resolución de dicho mito tiene por finalidad demostrar la escisión entre placer y trabajo, en tanto nota saliente del modo en que se desenvuelve la praxis social:

Lo que ha oído [Odiseo] no tiene consecuencias para él; sólo puede hacer señas con la cabeza para que lo desaten, pero ya es demasiado tarde: sus compañeros, que no oyen nada, conocen sólo el peligro del canto y no su belleza, y lo dejan atado al mástil para salvarlo y salvarse con él. Reproducen con su propia vida la vida del opresor, que ya no puede salir de su papel social. Los lazos con los que se ha ligado irrevocablemente a la praxis mantienen, a la vez, a las sirenas lejos de la praxis: su seducción es convertida y neutralizada en mero objeto de contemplación, en arte [...] De este modo, el goce artístico y el trabajo manual se separan al despedirse la prehistoria (87).

El hecho de que la esfera del trabajo quede ajena a la experimentación de toda forma de felicidad y satisfacción le permite erigirse como un espacio autonomizado que se regula únicamente por los principios de eficacia y productividad. Tal y como afirma Marx, la fórmula D-M-D', supone la existencia de una mercancía que permita crear valor adicional, es decir, la mercancía fuerza de trabajo, la cual, remite "al conjunto de facultades físicas y mentales que existen en la corporeidad, 
en la personalidad viva del ser humano" (Marx, 2009, p. 203). Como sostendrá Foucault, no hay ni puede sostenerse el capitalismo sin la reducción del cuerpo a una mercancía:

El capitalismo, que se desenvuelve a fines del siglo XVIII y comienzos del XIX, socializó un primer objeto, que fue el cuerpo, en función de la fuerza productiva, de la fuerza laboral. El control de la sociedad sobre los individuos no se opera simplemente por la conciencia o por la ideología sino que se ejerce en el cuerpo, con el cuerpo. Para la sociedad capitalista lo importante era lo biológico, lo somático, lo corporal antes que nada. El cuerpo es una realidad biopolítica (Foucault, 1996, p. 87).

La determinación del valor de cambio de la mercancía fuerza de trabajo, es decir, el tiempo de trabajo socialmente necesario para su reproducción, está dado por la cantidad de bienes de consumo que requiere para su subsistencia, también, por un "elemento histórico-moral" (Marx, 2009, p. 208). El análisis de los mecanismos de regulación de este último aspecto constituyen un factor esencial de la crítica a la ideología que lleva adelante Adorno, ya que mediante un conjunto de instituciones formales e informales, así como, a través de diversos procesos de sociabilización primaria y secundaria, tales como el deporte, la administración de la salud, la técnica, la educación, los medios de comunicación, entre otros, se movilizan un conjunto de prácticas cuya finalidad es la de producir un sujeto acorde a los requerimientos del desarrollo capitalista. Como es conocido, será el concepto de industria cultural la matriz central que engloba todas estas prácticas anteriormente referidas (y muchas otras más, por supuesto), desenvolviendo, en palabras de Jameson, una verdadera "teoría de la vida cotidiana" (2010, p. 224).

La capacidad crítica de dicho concepto radica en que supera ampliamente la clásica noción marxista de falsa conciencia, en tanto oclusión de una esencia verdadera o auténtica que estaría esperando emanar detrás un velo ideológico. La eficacia que posee el accionar de la industria cultural no está ligada al paradigma del ocultamiento/distorsión, sino a la "producción de consciencia" (Adorno y Benjamin, 1998, p. 113), de ahí que sea necesario estudiar el papel que cumple en la regulación de los resortes mismos de la estructura psíquica, es decir, el modo en que estos se ponen a trabajar a favor de alienación del sujeto, como se nota en la siguiente línea: "la industria de la cultura surgió de la tendencia explotadora del capital. La desarrolló bajo la ley del mercado, bajo la obligación de adaptarse a sus consumidores; luego, imbatida, pasó a ser la instancia que fija y refuerza a la conciencia en cada una de sus formas vigentes, en el statu quo" (Adorno, 2004, p. 17).

Adorno, siguiendo a Freud, sostendrá que el yo no es una instancia originaria y autónoma, sino una "forma de organización de todas las excitaciones psíquicas, como el principio de identidad que llega a constituir la identidad" (64-65), señalando, con ello, el papel que tiene el inconsciente en los procesos de integración y socialización de los individuos. Puesto que el yo se esfuerza por "hacer valer 
sobre el ello el influjo del mundo exterior, así como sus propósitos propios [y que] se afana por remplazar el principio de placer, que rige irrestrictamente en el ello, por el principio de realidad" (Freud, 1982, p. 27), se comprende que la identidad del sujeto solo se logra cristalizar a partir de la interiorización de mandatos sociales, bajo la instancia del súper-yo: "la sociedad racional, que se basa en el dominio de la naturaleza interior y exterior [...] doma hasta el difuso principio del placer que es perjudicial para la moral del trabajo" (Adorno, 2009, p. 470). De este modo, se conforma un individuo capaz de actuar según las necesidades de la reproducción del capitalismo.

La estocada final que permite asegurar la victoria del statu quo, la otorga los bienes y servicios producidos por la industria cultural, la denominada pseudocultura, ya que tienen por cometido ofrecer las compensaciones necesarias y requeridas para la refuncionalización del individuo:

No se trata de que la industria de la cultura ofrezca «contenidos ideológicos», sino de que suministra a los individuos socializados la sustancia en torno a la cual gira su praxis vital cotidiana, el marco que rige su interacción y los modelos de catarsis e identificación que compensan las carencias de unos sujetos desposeídos de toda capacidad de acción y a los que la praxis social exige un nivel de sacrificio y renuncia sin precedentes. Lo que su red de socialización ofrece a los individuos socializados es un «fundamento común» que ya no es suelo sino red, un «mundo de la vida» que no puede ser hipostasiado como algo espontáneo, sino que está unido a la imposición de una división bifásica de la existencia entre tiempo de producción (trabajo) y tiempo de consumo (tiempo libre) y supone la imposición «de un sachliche Stil de vida y de percepción» que refuerza patrones rígidos de pensamiento y acción caracterizados por la atrofia de la experiencia (Maiso, 2010, p. 375).

Al tomar como base esta caracterización, se comprende que la industria cultural no se conforma con entregar simples placebos al sujeto, sino que le otorga un horizonte de expectativas compartidas por un conjunto mayor, por lo que éste termina por incorporar y cumplir con los mandatos impuestos como si fueran propios, inclusive cuando atentan contra la posibilidad de experimentar cualquier forma no regulada de felicidad o placer. Las renuncias particulares, vividas como un "agravio narcisista", son diluidas y reconstituidas a partir del narcisismo colectivo, delineando una pseudo-individualidad ${ }^{4}$.

\footnotetext{
${ }^{4}$ Un excelente estudio de la relación específica entre el psicoanálisis freudiano y la obra de Adorno puede encontrarse en Zamora, 2007b, pp. 27-42, así como en Maiso, 2012, pp. 197-212 y 2013, pp. 132-150.
} 
Así, pseudo-individualidad, narcisismo colectivo y pseudo-cultura conforman, en esta perspectiva, una constelación conceptual que se retroalimenta:

La pseudo-cultura ha convertido en propiedad de todos el secreto reino de este narcisismo. El narcisismo colectivo apunta a que las personas compensen la conciencia de su impotencia social —que se extiende hasta sus constelaciones pulsionales individuales-, y a la vez el sentimiento de culpa por no ser y no hacer lo que debieran ser y hacer según el propio concepto, convirtiéndose realmente, o en la simple imaginación, en miembros de algo superior, abarcante, a lo que atribuyen las propiedades de todo lo que les falta, y de lo que, a modo de representantes, reciben algo a cambio en forma de participación en esas cualidades (Adorno, 2004, pp. 106-107).

En este complejo entramado de dominación y construcción del sujeto, donde "el principio económico de la apropiación había devenido antropológico" (Adorno, 2008, p. 256), se produce la paradoja de que, a causa de las muchas renuncias absurdas que le son impuestas al yo, este "ha de establecer prohibiciones inconscientes y mantenerse él mismo en la inconsciencia" (65). La principal consecuencia de ello será la generación de una falsa armonía entre el principio de placer y el de realidad, desviando las verdaderas metas pulsionales "mediante la expropiación de lo inconsciente a través del control social" (403). De este modo, aquellas son puestas al servicio de la conformación de una sociedad de individuos aislados entre sí, que encuentran refugio en una personalidad narcisista, la cual atenta contra el surgimiento de una consciencia crítica y reflexiva:

El yo que se retrae a sí mismo al inconsciente no se limita a desaparecer, sino que conserva alguna de las cualidades que había adquirido como agente social. Pero las somete al primado del inconsciente. Así es como surge la apariencia de una armonía entre el principio de realidad y el principio del placer. Con la transposición del yo al inconsciente se trasforma a su vez la cualidad de la pulsión, que asimismo se ve desviada a metas propiamente yoicas que contradicen a aquello a que se dirige la libido primaria. La forma de la energía pulsional en la que se apoya el yo según el tipo analítico freudianao, cuando avanza hacia el sumo sacrificio, de la conciencia misma, es el narcisismo (66-67).

Por tanto, el mantenimiento del orden requiere de la represión de las pasiones e instintos del hombre, ya que permiten la emergencia de prácticas que contrarían los cimientos mismos de lo existente:

Cuanto más complicado y sutil es el aparato social, económico y científico, a cuyo manejo el sistema de producción ha adaptado desde hace tiempo el cuerpo, tanto más pobres son las experiencias de las que éste es capaz [...] La impotencia de los trabajadores no es sólo una artimaña de los patrones, 
sino la consecuencia lógica de la sociedad industrial [...] Pero esta necesidad lógica no es definitiva. Permanece ligada al dominio, a la vez como su reflejo e instrumento (Adorno y Horkheimer, 2001, p. 89).

El rechazo experimentado por el hombre se debe a que el placer somático materializa un momento de disolución del sí mismo, del borramiento de su identidad conseguida mediante el frío cálculo de la razón: "los seres humanos poseen roles dentro de una interconexión estructural de la sociedad, que los adiestra para la pura autoconservación y les niega a la vez la conservación del propio yo" (Adorno, 2004, pp. 12-13). Sin embargo, existe una causa mucho más profunda que sostiene la reacción contra el aspecto sensible del sujeto. Teniendo en cuenta que "la fuerza del miedo y la de felicidad son la misma, un ilimitado y creciente estar abierto a la experiencia hasta el abandono de sí mismo, a una experiencia en la que el caído se recupera" (Adorno, 1999, p. 201), se comprende que el aspecto sensorial del hombre permite trascender la mónada que constituye el yo abstracto, habilitando un momento de fusión, solidaridad y apertura hacia lo otro de sí. A través de su accionar se pone en juego la posibilidad de establecer relaciones no violentas entre la naturaleza y los hombres, así como entre ellos mismos $^{5}$. Por el contrario, la división social del trabajo tiene por finalidad someter en cuerpo y alma al sujeto, pues:

[E]l trabajo social de todo individual es, en la economía burguesa, mediatizado gracias al principio del Sí; debe restituir, a los unos el capital acrecentado, a los otros la fuerza para el trabajo. Pero cuanto más se realiza el proceso de la autoconservación a través de la división burguesa del trabajo, tanto más dicho progreso exige la autoalienación de los individuos, que deben adecuarse en cuerpo y alma a las exigencias del aparato técnico (Adornoy Horkheimer, 2001, p. 83).

Basándonos en lo antedicho se comprende que la asignación de roles prefijados a cada uno, que delimitan lo permitido y lo prohibido bajo rígidos parámetros, está a la base de la pérdida de la capacidad de la experiencia (erfahrung). Se corporiza, perversamente, el proyecto leibniziano: la armonía preestablecida, objeto de su monadología, se consuma aquí debido a que el antagonismo que regula el todo social, habita en el seno mismo de cada individuo. A diferencia suya, en este caso, no se requiere de ninguna teodicea o entidad metafísica que permita superar la dualidad cuerpo y alma, sino que es la propia división del trabajo la que asegura la cohesión, homogenización y reproducción social, ya que hace de la lógica del cálculo, el principio rector que permea hasta la fibra más íntima del hombre, constituyéndolo bajo la órbita de un sí mismo desprovisto de toda singularidad.

\footnotetext{
${ }^{5}$ Un pormenorizado estudio acerca de la utilización del concepto de naturaleza dentro del contexto de la teoría crítica adorniana puede encontrarse en Cook (2011).
} 


\section{Impulso moral: cuerpo y memoria como elementos de una ética materialista}

La situación descrita anteriormente permite comprender de modo cabal el lugar que ocupa el cuerpo como objeto de dominación necesario, en pos de preservar los fundamentos vigentes del régimen de producción social:

El odio-amor hacia el cuerpo tiñe toda la civilización moderna. El cuerpo, como lo inferior y sometido, es convertido de nuevo en objeto de burla y rechazo, y a la vez es deseado como lo prohibido, reificado, alienado. Sólo la civilización conoce el cuerpo como una cosa que se puede poseer, sólo en la civilización se ha distinguido y separado el cuerpo del espíritu - quintaesencia del poder y del mando- como objeto, cosa muerta, corpus. En la autodegradación del hombre a la categoría de corpus se venga la naturaleza del hecho de haber sido degradada y reducida por el hombre a objeto de dominio, a materia prima (Adorno y Horkheimer, 2001, p. 278).

La importancia capital que Adorno le otorga al análisis de la represión de lo somático no solo tiene la finalidad de demostrar su inextricable relación con la conciencia cosificada, base de la frialdad burguesa y la indolencia total ante los padecimientos de los demás, sino que, principalmente, constituirá el punto saliente a partir del cual edificará su propuesta de una ética verdaderamente materialista.

Es este marco teórico el que brinda los argumentos critico-normativos de la postura adorniana frente a la experiencia de Auschwitz. En sus "Meditaciones sobre la metafísica", último modelo de Dialéctica negativa, Adorno sostendrá que Hitler ha impuesto un nuevo imperativo categórico a la humanidad:

Orientar su pensamiento y su acción de tal modo que Auschwitz no se repita, que no ocurra nada parecido. Este imperativo es tan reacio a su fundamentación como otrora el dato del kantiano. Tratarlo discursivamente sería un crimen: en él puede sentirse corporalmente el momento de lo adicional en lo ético. Corporalmente porque es el aborrecimiento, hecho práctico, del inaguantable dolor físico al que están expuestos los individuos incluso después de que la individualidad, en cuanto forma espiritual de la reflexión, está a punto de desaparecer. Sólo en el motivo materialista sin tapujos sobrevive la moral (Adorno, 2008, pp. 334-335).

La particularidad de este imperativo gira en torno a la dimensión corporal del sufrimiento perpetrado; sin embargo, esto no debe llevar a confusiones: la filosofía de Adorno no es una pedagogía del dolor, sino un posicionamiento radical en su contra. El lenguaje que emana de estos padecimientos físicos permite romper la pretendida suficiencia de toda filosofía del sujeto y su discurso, echando en cara las mentiras en las que se asienta, ya que "la más mínima huella de sufrimiento sin 
sentido en el mundo de la experiencia desmiente toda la filosofía de la identidad, que querría disuadir de él a la experiencia" (191). El sufrimiento es el aguijón que acicatea el postulado de la necesidad de lo ocurrido y, por tanto, habilita su interrupción. Se constituye, de esta manera, como el aspecto material ineliminable de aquella disciplina, la filosofía, que precisamente se ha abocado tradicionalmente a habitar mundos espirituales e incorpóreos. Dejar que el dolor se exprese es darle elocuencia a aquello que ha sido siempre violentado, "el momento corporal recuerda al conocimiento que el sufrimiento no debe ser, que debe cambiar. «El dolor habla: pasa»" (191). Por tanto, el dolor, aporta la negatividad necesaria que pone en movimiento la dimensión crítica y no dogmática de la dialéctica.

El hecho de que Adorno manifieste la relación entre moralidad y corporalidad en términos de un imperativo categórico, remite en forma directa a su discusión con Kant y la tradición idealista por él iniciada. En 1785, el hombre de Königsberg, publicará su célebre Fundamentación de la metafísica de las costumbres donde expondrá su propio imperativo categórico, el cual, en su última formulación, sostiene que se debe "obrar según aquella máxima por la cual puedas querer que al mismo tiempo se convierta en una ley universal" (Kant, 2002, p. 104, énfasis original). Este imperativo es universal e incondicional, es decir, necesario y autofundante. De él se deben deducir todas las normas que guían la acción moral, dando origen a su famosa sentencia, "obra como si la máxima de tu acción pudiera convertirse por tu voluntad en una ley universal de la naturaleza" (104, énfasis original). El fundamento de su obligatoriedad es producto de su derivación directa de la razón pura, es decir, a priori de toda experiencia. Por ende, los hombres son libres, ya que tienen la capacidad de regir sus acciones a partir de las pautas que se dan a sí mismos, sin someterse a ninguna legislación ajena.

Las diferencias entre este imperativo con respecto al adorniano saltan a la vista $^{6}$. Como punto de partida se puede afirmar que este último se halla interpelado por la experiencia del mal, lo cual significa dos cosas: la primera, que constituye una legalidad surgida en respuesta al genocidio nazi, en otros términos, no es una ley que emana de la razón pura, sino que es una reacción ante una experiencia histórica específica. Por lo tanto no es autofundante, sino profundamente heterónoma. En segundo lugar, este imperativo tiene un fuerte carácter negativo, ya que no está motivado por la búsqueda de lo bueno, por afirmar cuáles son los requerimientos que debe cumplir una conducta para ser considerada moral, sino que está basado en un decir "no", en la negación determinada frente a lo sucedido, exigiendo evitar su repetición.

\footnotetext{
${ }^{6}$ Para un análisis exhaustivo de la relación entre el imperativo categórico kantiano y sus diferencias y continuidades con el adorniano, véase, Tafalla (2003, pp. 23-66).
} 
Al constituir una intensa reacción contra el dolor y el sufrimiento perpetrado, dicho imperativo deviene profundamente materialista. De esta manera, su determinación última halla refugio en el impulso somático, desencadenando una respuesta corporal profundamente solidaria respecto a las víctimas de las injusticias acaecidas. Esta posibilidad tiene su fundamento en el reconocimiento de que "todo lo espiritual es impulso corporal modificado, y tal modificación la conversión cualitativa en lo que no meramente es. El impulso, en la acepción de Schelling, es la protoforma del espíritu" (Adorno, 2008, p. 190). Este impulso, será el que despliegue el mecanismo que Adorno denomina reacción mimética, el cual permite que las normas verdaderamente éticas surjan frente a una situación concreta, sin ser derivables de ningún juicio apodíctico:

Las preguntas morales se plantean sin rodeos, no en su repugnante parodia, la represión sexual, sino en frases como: no torturarás; no habrá campos de concentración, mientras todo eso sigue ocurriendo en África y Asia y no se hace más que reprimirlo porque el humanitarismo civilizador es como siempre inhumano con los por él desvergonzadamente estigmatizados como incivilizados. Pero si un filósofo moral se apoderase de esas frases y se alegrase de haber pillado a los críticos de la moral — también ellos citaban los valores con gusto predicados por los filósofos de la moral-, la contundente conclusión sería falsa. Las frases son verdaderas como impulso cuando se anuncia que en algún lugar se ha torturado. Lo que no pueden es racionalizarse; en cuanto principio abstracto, incurrirían enseguida en la mala infinitud de su deducción y validez. La crítica de la moral va dirigida contra la transposición de la lógica de la consecuencia a la conducta de los hombres; la astringente lógica de la consecuencia se convierte ahí en órgano de la no-libertad (Adorno, 2008, p. 263).

En tanto agitación espontánea, la inervación somática se vehiculiza de modo urgente e impaciente, dado que la superación práctica del sufrimiento no tolera ningún aplazamiento ni fundamentación teórica: "el impulso, el desnudo miedo físico y el sentimiento de solidaridad con los cuerpos, como decía Brecht, torturables, que es inmanente a la conducta moral, lo negaría la aspiración a una racionalización sin contemplaciones; lo más urgente se convertiría de nuevo en contemplativo, burla de la propia urgencia" (263).

Ahora bien, el peligro que corre esta simpatía con lo más débil es quedar recluida como una simple manifestación de la compasión. Schopenhauer y Nietzsche le darán fundamentos para especificar los límites de este vínculo:

Se debe admitir que la crítica de Nietzsche a la moral de la compasión tiene un elemento de verdad. Esto es porque el concepto de compasión tácitamente mantiene y da su sanción a la condición negativa de impotencia en la cual la persona compadecida se encuentra. La idea de compasión no dice nada acerca de la necesidad de cambiar las circunstancias que le dan su origen, sino que, en su lugar, como en Schopenhauer, esas circunstancias 
son absorbidas dentro de la doctrina moral e interpretadas como su fundamento. En suma, ellas son hipostasiadas y tratadas como si fueran inmutables. Se puede concluir que la compasión que se expresa a alguien contiene un elemento de injusticia hacia esa persona; esta experimenta no solo la compasión sino también la impotencia y el carácter ilusorio de esa acción compasiva (Adorno, 2000, pp. 173-74, traducción propia).

A diferencia del imperativo categórico kantiano que, en el mismo gesto por el cual pretende legislar para toda la humanidad, traiciona la singularidad de cada individuo, este impulso somático será el que permita acercarse y dejarse afectar por los padecimientos de cada uno de ellos. Sin embargo, la compasión, al quedar en el plano de una reacción estrictamente personal, se torna contingente y sin capacidad de superar esas injusticias. De esta manera, se aproxima peligrosamente al pesimismo y a la pasividad, al aceptar la inevitabilidad de lo ocurrido. Esta simpatía con lo sufriente no permite dar respuestas a los porqué de la situación actual, ni avizorar posibles alternativas, de ahí que requiera su anudamiento con la memoria y el recuerdo, dado que aportan una capacidad crítica para volver sus limitaciones en fuente de una moral donde se conjuguen la aproximación a lo particular, propia de la mímesis, con la visión de conjunto que trae a colación el recuerdo de los padecimientos pretéritos.

De lo expuesto se desprende que el imperativo categórico adorniano resitúa el papel del pasado no como una entidad circunscrita a un período determinado, sino como algo abierto y con incidencia en el presente y el futuro. Es por ello que exige negar las estructuras dominantes que le dan sustento al estado de ofuscación vigente, evitando así, la posibilidad de su reiteración. Por el contrario, el olvido se constituye en el principal nutriente del mal, dada su potencialidad de tornar las tragedias pasadas en meras fechas conmemorativas o en simples efemérides: "el olvido es inhumano porque se olvida el sufrimiento acumulado, pues la huella histórica en las cosas, palabras, colores y tonos es siempre la del sufrimiento pasado" (Adorno, 2009, p. 275). En cambio, la memoria busca interrumpir la circularidad de lo mismo, abriendo paso a lo nuevo, a la emergencia de lo distinto: el recuerdo de las injusticas pasadas, es la condición de posibilidad de una justicia futura ${ }^{7}$.

Ahora bien, no se debe perder de vista que Adorno no tiene una esperanza irrestricta o ingenua en la reposición de lo corporal como elemento que baste para contrarrestar la coacción de la totalidad imperante. Este impulso, liberado a su simple inmediatez, es ciego, y no constituye por sí mismo ninguna virtud moral. La finalidad de la dialéctica negativa no es dejar de lado la racionalidad, sino reorientar su tendencia, anclar el pensamiento a la fuente a-conceptual de la cual emerge. Su proyecto es establecer una tensión dialéctica entre ambos polos, si se

\footnotetext{
La categoría de justicia está trabajada desde una perspectiva próxima a una razón anamnética. Para un desarrollo mayor de esta cuestión, véase Zamora, 2004, pp. 279-297.
} 
sigue la afirmación reproducida a continuación: "Lo inseparado vive únicamente en los extremos, en la pulsión espontánea que, impaciente con el argumento, no quiere tolerar que el horror perdure y en la consciencia teórica no aterrorizada por ninguna orden, que comprende por qué, sin embargo, perdura indefinidamente" (Adorno, 2008, p. 263).

De este modo, la racionalidad permite construir, a partir del rechazo somático respecto de los sufrimientos perpetrados, la expresión de una negatividad que no debe ser: "El objeto de la teoría no es lo bueno, sino lo malo [...] Su elemento es la libertad; su tema, la opresión. [...] Hay una sola expresión para la verdad: el pensamiento que niega la injusticia" (Adorno y Horkheimer, 2001, p. 261). Dejando atrás todo vestigio de idealismo, Adorno sostendrá que la teoría no debe buscar explicaciones que justifiquen lo existente, sino que, desmitificando el carácter de necesariedad o de segunda naturaleza del presente, permita observar la violencia que lo conforma. El pensamiento, en tanto crítica no resignada, es capaz de lograr resistir los designios instrumentales, erigiéndose como sede de una actividad libre y no reglamentada.

\section{Libertad, praxis y corporalidad. El papel de la espontaneidad}

La relación inherente entre moralidad y corporalidad, tal y como fue expuesta anteriormente, tendrá una repercusión insoslayable en la re-conceptualización de la noción de libertad, ya que Adorno, inscrito en la tradición iniciada por Kant, pondrá en correlación ambos términos: libertad y moralidad.

Si el hombre de Frankfurt ha señalado que no cabe la vida justa en la vida dañada, tal sentencia no debe ser interpretada como el simple reconocimiento de la inevitabilidad de lo que ha sido. Dicha afirmación no tiene un contenido meramente descriptivo, sino profundamente normativo. Por ello, lo que pretende subrayar es la necesidad de tomar conciencia de la situación existente, erigiendo a la inervación somática como el lugar privilegiado desde donde emerja la verdad de la coacción ejercida: "la necesidad de prestar voz al sufrimiento es condición de toda verdad. Pues el sufrimiento es objetividad que pesa sobre el sujeto; lo que éste experimenta como lo más subjetivo suyo, su expresión, está objetivamente mediado" (Adorno, 2008, p. 28).

De acuerdo con Adorno, si bien la sociedad se ha vuelto un todo compacto regulado por el principio de identidad y, por tanto, por el principio del intercambio de equivalentes, esto no significa que no haya espacio para su modificación: 
Sería una abstracción mala e idealista quitarle importancia o incluso acentuar negativamente la posibilidad de mejoras en el marco de la situación existente en aras de la estructura de la totalidad. Se estaría utilizando un concepto de totalidad que ignora por completo los intereses de los seres humanos vivientes aquí y ahora, lo cual implica un tipo de confianza abstracta en el rumbo de la historia universal, que yo, al menos en esta forma, decididamente no puedo aceptar (Adorno, 1996, p. 45).

Lo que está detrás de esta perspectiva es el llamado a repensar una praxis verdadera y auténtica que permita trascender lo existente, pues, de otro modo, se estaría dotando a la facticidad imperante de una determinación necesaria, conclusión que será, según la lectura de Adorno, la verdad oculta a la que arriba la filosofía kantiana.

Si se siguen los planteamientos ya expuestos, se debe tener en cuenta que el modo de asegurar la libertad de la voluntad, según Kant, solo es posible si se concibe a la fuente de su motivación "no según la materia sino solo según la forma" (Kant, 1951, p. 31). El hecho de que logre separar tan prístinamente voluntad y dimensión corporal, se sigue del principio de identidad que rige sus postulados, dado que los impulsos e instintos que recuerdan la naturalidad del hombre deben ser reprimidos quedando relegados al ámbito de la inclinación y el gusto.

La principal preocupación de la arquitectónica kantiana será fundar la libertad humana, separándola tajantemente del espacio de la causalidad natural. Para hacer esto establece una estricta división entre el mundo fenoménico, regido por leyes naturales y el mundo nouménico, donde las acciones pueden establecerse según motivaciones libres. De esta manera, el hombre se encuentra sobrepujado por su pertenencia a dos reinos distintos: un ente físico está sometido al determinismo propio del mundo de los fenómenos; mientras que su facultad moral queda resguardada al responder a los requerimientos propios del mundo inteligible. Por otra parte, la intervención adorniana se enfocará, particularmente, en revelar lo que esconde este postulado: afirmar que el hombre es libre porque está regido por una ley de la razón, es trasponer al ámbito de lo nouménico el determinismo propio de la causalidad natural. En consecuencia, el imperativo categórico no se vuelve fuente de libertad, sino de obediencia: "tras los bastidores del sistema kantiano se espera que el concepto supremo de la filosofía práctica coincida con el supremo de la teórica, el principio del yo, el cual tanto crea unidad teóricamente como prácticamente reprime e integra los instintos. La unidad de la persona es el lugar de la doctrina de lo inteligible" (Adorno, 2008, p. 269).

Igualmente, el mismo principio de identidad que rige la conformación del objeto de conocimiento en la Crítica de la razón pura es aquel que opera como condición de posibilidad de la libertad kantiana, ya que la voluntad, para ser libre, es decir, para formar parte de lo inteligible, debe ejercer una abstracción de las determinaciones empíricas del individuo, si se advierte que "conforme a la concepción global, el 
concepto de libertad únicamente puede representarlo como represión. Todas las concreciones de la moral tienen en Kant rasgos represivos. Su carácter abstracto afecta al contenido porque elimina del sujeto lo que no corresponde a su concepto puro" (238).

Como se ha mencionado anteriormente, Adorno, apoyado en la crítica desmitificadora que realiza Freud, inscribió a la conciencia no como un primer principio, sino como algo devenido y surgido, ubicando el problema de la estructuración libidinal de los hombres a partir de la recurrencia entre lo interno (las determinaciones psíquicas del individuo) y lo externo (los mecanismos de sujeción imperantes). Si desde Tótem y tabú, el padre del psicoanálisis ha dejado claro que el imperativo categórico no es más que el heredero del superyó o la conciencia moral, la prédica kantiana de una libertad interiorista debe ser rechazada ya que esta es la "interiorización ciega e inconsciente de la coacción social" ( 252).

Esta conclusión le permitirá a Adorno realizar una intervención crítica sobre la noción de espontaneidad, sustrayéndola del lugar asignado en la arquitectónica kantiana. Si las determinaciones sociales se muestran como las represiones ocultas que se ponen en funcionamiento en la conciencia pura, no por ello hay que resignar la utilización de dicha categoría; antes bien, es necesario reinscribirla como el lugar de anudamiento entre la libertad moral y la dimensión corporal de la experiencia. Según se observa en seguida:

Lo que es diferente de la consciencia pura en la acción, lo cual desde el punto de vista kantiano obliga a ésta, lo que brota súbitamente, es la espontaneidad, que Kant trasplantó igualmente a la consciencia pura, pues de lo contrario la función constitutiva del «yo pienso» se habría puesto en peligro. En éste el recuerdo de lo excluido sólo sigue viviendo en la doble interpretación de la espontaneidad intramentalmente interpretada. Por una parte, es obra de la consciencia: pensar; por otra, inconsciente e involuntariamente, el latido de la res cogitans más allá de ésta. La misma consciencia pura —la «lógica»— es algo devenido (215).

Avizorar la incidencia de lo somático en la determinación de la acción libre y no cercenada le permitirá a Adorno desmarcar su concepción de la kantiana, estableciendo una mediación diferenciada entre impulso y razón: "las decisiones del sujeto no engranan en la cadena causal, se produce un salto. Esto añadido, fáctico [...] a la vez intramental y somático, empuja más allá de la esfera de la consciencia, a la cual sin embargo también pertenece. Con él se introduce la libertad en la experiencia" (212-214).

Sin embargo, es necesario enfatizar que Adorno no hace un salto unilateral del idealismo transcendental al psicoanálisis freudiano, como si este fuera un corpus dogmático incuestionable e irrebatible. Lo que existe es un doble movimiento, 
por el cual se critica a Kant, con base en los postulados de Freud y viceversa. Así, Adorno sostendrá que lo inteligible, en tanto voluntad racional purgada de todo contenido fenoménico, se torna una entelequia paralizada sin posibilidad de llevar adelante modificación alguna sobre el mundo material que, paradójicamente, es el espacio donde se desenvuelve el comportamiento moral de los hombres: "El carácter inteligible acaba por ser la voluntad racional paralizada. Lo que por el contrario pasa en él por lo superior, más sublime, incontaminado por lo inferior, es esencialmente su propia indigencia, la incapacidad para cambiar lo degradante; renuncia que se estiliza como fin en sí" (274).

Empero, como bien sostiene Schweppenhäuser, el frankfurtiano encuentra altamente positivo el gesto kantiano de rechazar a la conciencia empírica como patrón de medida de todo comportamiento moral. Puesto que, el imperativo categórico contiene un componente critico relevante; dado que, anticipadamente, describe cómo se debería actuar dentro de una sociedad de hombres libres y autónomos: "el contenido de verdad, crítico y anticipador, de una filosofía moral racionalmente establecida no puede ser atribuida a la subjetividad, siempre dañada, de una "personalidad empírica". Esta no puede ser el criterio por el cual medir la moralidad" (Schweppenhäuser, 2003, p. 406. Traducción propia).

Del mismo modo en que el rodeo por Freud demostraba la verdad oculta del proyecto idealista, el movimiento contrario arroja luz sobre el punto exacto en el cual el corpus psicoanalítico acierta en su desacierto. La célula aislada en la que se ha convertido el sí mismo, reducido a un simple ser genérico separado del resto, coincide con la perspectiva individualista que aplica Freud como método de estudio. El suyo es un análisis coincidente con la psicología propia del sujeto reificado: "Freud tenía razón cuando se equivocaba [ya que] ha dado expresión adecuada, mediante su atomística psicológica, a una realidad en la que los hombres están de hecho atomizados y se encuentran separados entre sí por un abismo infranqueable" (Adorno, 2004, p. 33).

La estrategia utilizada por Adorno será conjugar diversos pensadores en una constelación dialéctica que, en su tensión mutua, permita conmover la referencia de cada concepto resignificándolo, críticamente, a la luz de su opuesto. De esta manera, las cualidades de la esencia inteligible, es decir, la autonomía y la libertad, aparecen como propiedades del impulso corporal, antes que correspondientes a la esfera de lo nouménico:

Lo que en los hombres cabría pensar como carácter inteligible no es lo que en ellos hay de personal, sino aquello por lo que se distinguen de su ser-ahí. En la persona este distintivo aparece necesariamente como algo no-idéntico. Toda pulsión humana contradice la unidad de quien la siente; todo impulso a lo mejor no es sólo, kantianamente, razón, sino ante ésta también una necedad. Los hombres sólo son hombres cuando no obran 
como personas ni siquiera se ponen como tales; lo difuso de la naturaleza, en la cual no son personas, se asemeja al perfil de una esencia inteligible, de aquella mismidad que se desprendería del yo (Adorno, 2008, p. 256).

A su vez, el terreno de lo pulsional, que en su actualidad se encuentra plegado a los requerimientos de la autoconservación, refuerza el conformismo con que los hombres viven su situación de explotación: "los instintos que impulsan a salir de la falsa situación tienden a encauzarlos hacia un narcisismo satisfecho con la falsa situación. Este es un gozne en el mecanismo del mal: una debilidad que, donde es posible, se toma por fortaleza" (274).

A través de estas mediaciones conceptuales, donde cada término contiene su contrario, Adorno consuma su rechazo a toda forma de filosofía del origen, que no es más que un rechazo a toda filosofía de la identidad, edificada en torno a un primer principio, sea el inconsciente, sea la voluntad racional, señalando el carácter constituyente y a la vez constituido de cada uno de ellos. Gracias a este proceder, lo que se intentará, en definitiva, es erigir un concepto de corporalidad que esté por fuera del paradigma reinante, en el cual el individuo se expresa, perversamente, sólo a través del síntoma, haciendo que "la enfermedad del normal no se contrapon[ga] sin más [a] la salud del enfermo, sino que ésta la mayoría de las veces simplemente representa el esquema del mismo infortunio en otra forma" (Adorno, 1999, pp. 57-58). Esta situación tiene su condición de posibilidad en el reconocimiento de que el entramado histórico-natural repercute en la determinación de la estructura psíquica del individuo: "la dimensión psicológica del fenómeno no debe separarse rotundamente de la histórico-social: las constelaciones sociales específicas favorecen selectivamente la formación de síndromes psicológicos adecuados a ellas o, por lo menos, los sacan a la luz" (Adorno y Horkheimer, 1969, p.173).

Como se hizo notar, es preciso entender que cuando el sujeto reduce su cuerpo a una mercancía más, regulada por las necesidades del capital, paga un precio demasiado alto, según Adorno, el fenómeno descrito deriva en el hecho de que la represión de sus aspiraciones pulsionales tiene como consecuencia trasponer "sus componentes libidinosos [...] en síntomas, y sus componentes agresivos, en sentimiento de culpa" (Freud, 1992, p. 134).

En este modelo, paradójicamente, el hombre encuentra como única posibilidad de canalizar sus impulsos insatisfechos la formación de síntomas que, en tanto "satisfacciones sustitutivas, los hacen padecer por sí mismas o devienen fuentes de sufrimiento por depararles dificultades con el medio circundante y la sociedad" (105). Frente a esta descripción, Adorno pretenderá despejar, como se ha dicho, la problemática de la corporalidad bajo una nueva modalidad, donde la pasividad sufriente no sea su nota distintiva sino que, al tener la característica de no contribuir a la supervivencia de las injusticias acaecidas, se constituye 
en la sede de la resistencia frente a la menesterosidad de lo real. Dado que "la libertad se concreta en las figuras cambiantes de la represión: en la resistencia contra éstas" (Adorno, 2008, p. 246), la dimensión somática introduce en el mundo administrado una actividad no reglamentada que desmiente el carácter ideológico de la cerrazón de la inmanencia, ya que "sin anamnesis del impulso indómito, preyoico, el cual luego es desterrado a la zona de sujeción sin libertad, a la naturaleza, no se podría alentar la idea de libertad" (208). De este modo, la impotencia práctica de los hombres se logra revertir, al establecer una fuente de su accionar que contraría la pervivencia de lo siempre igual. Como se ilustra aquí: "la praxis ha también menester de otra cosa, de algo que no se agota en la consciencia, corporal, convertido por la mediación en la razón y cualitativamente distinto de ésta" (215).

\section{El recuerdo de la naturaleza en el sujeto. Agresividad y lazo social}

El esclarecimiento de lo somático, en tanto común denominador de la libertad y la moralidad, permite repensar la incidencia de lo somático en la conformación de las prácticas intersubjetivas. A diferencia de los miembros de la segunda y tercera generación del Institut für Sozialforschung (Habermas, Wellmer, Honneth, etc.), quienes localizan en la racionalidad comunicativa el paradigma explicativo de dicho vínculo, Adorno, dentro su materialismo, desarrolla esta reflexión íntimamente ligada a la dialéctica sujeto-objeto, si se percata de que únicamente se podrá establecer una relación modificada entre los hombres una vez que se reconozca a su naturaleza interna como el momento de no identidad consigo mismo, en tanto condición sine qua non para el sobrepujamiento de su conceptualización atomista y puramente espiritualizada.

Hacer eje en la inervación somática permite desmentir la génesis de la subjetividad moderna como un principio autónomo; puesto que, desde el punto de vista sincrónico, el impulso corporal se muestra como un sustrato pre-racional; pero, al seguir el punto de vista diacrónico, remite a un estadio donde ambos polos, cuerpo y razón, no estaban separados: "este [el impulso] desmiente el dualismo cartesiano entre res extensa y res cogitans, que agrega lo añadido, en cuanto algo mental, a la res cogitans, sin tener en cuenta su diferencia del pensamiento. Lo añadido es impulso, rudimento de una fase en la que el dualismo entre lo extramental y lo intramental aún no estaba fijado por completo, ni franqueable con la voluntad ni algo ontológicamente último" (Adorno, 2008, p. 214).

No obstante, esta visión genealógica no apunta a recuperar un origen armonioso y no contaminado por las desavenencias del progreso histórico. Una solución de ese tenor sería absolutamente ideológica y contraproducente, puesto que, "la libertad sólo puede realizarse mediante la coacción civilizadora, no como retour a la nature" (143). 
El movimiento crítico aquí desarrollado busca reposicionar la mediación entre sujeto y objeto y no desandarla. Es en su radicalización donde cobra sentido el mandato final de Dialéctica de la llustración, acerca de la necesidad de recordar la naturaleza en el sujeto, ya que, gracias a este gesto "la llustración se opone al dominio en cuanto tal" (Adorno y Horkheimer, 2001, p. 93).

En este punto es donde surge nuevamente el trasfondo psicoanalítico que alienta la reflexión adorniana. Freud, en su ensayo Recordar, repetir y reelaborar, afirmará que el sujeto "repite todo cuanto desde las fuentes de lo reprimido ya se ha abierto paso hasta su ser manifiesto: sus inhibiciones y actitudes inviables, sus rasgos patológicos de carácter y, además, durante el tratamiento repite todos sus síntomas" (Freud, 1990, p. 153). Esta repetición hace referencia a la imposibilidad que tiene el sujeto de superar sus padecimientos pasados que, en tanto reprimidos, los "actúa" en el presente, en lugar de recordarlos: "el analizado no recuerda, en general, nada de lo olvidado y reprimido, sino que lo actúa. No lo reproduce como recuerdo, sino como acción" (155). Esta descripción encuentra su réplica, punto por punto, en el análisis que realizan Adorno y Horkheimer acerca de la constitución onto-filogenética del sí mismo: "la humanidad ha debido someterse a cosas terribles hasta constituirse el sí mismo, el carácter idéntico, instrumental y viril del hombre, y algo de ello se repite en cada infancia. El esfuerzo para dar consistencia al yo queda marcado en él en todos sus estadios, y la tentación de perderlo ha estado siempre acompañada por la ciega decisión de conservarlo" (Adorno y Horkheimer, 2001, p. 84). De acuerdo con la línea de argumentación esgrimida, la exigencia de recordar la naturaleza en el sujeto tiene la finalidad, no de buscar una unión inmemorial entre el hombre y su medio ambiente, sino señalar su afinidad, su "proximidad de la distancia" (Adorno, 1999, p. 88); de ahí que confluyan el concepto freudiano de durcharbeiten, entendido como un trabajo de elaboración mediante el cual se logre "suprimir la insistencia repetitiva propia de las formaciones inconscientes, poniéndolas en relación con el conjunto de la personalidad del sujeto" (Laplanche y Pontalis, 2004, p. 438), con la noción benjaminiana de Eingedenken.

Este último término, utilizado por Adorno y Horkheimer en Dialéctica de la Ilustración, para referirse a la tarea del recuerdo, y expresado por Benjamin en la quinceava de sus Tesis sobre filosofía de la historia ${ }^{8}$, hace referencia a una temporalidad que rompe el continuum de la historia, ya que es un instante en el cual la verdad se carga de tiempo, donde emerge algo pretérito, pero no como un hecho efectivamente acaecido, sino como incumplido, trunco y, por tanto, asediante 9 . En este "ahora", se conjugan el así fue y el aun no, es decir, una unión de pasado y futuro, que apunta a un tipo de redención ligada, como se verá más adelante, al concepto de felicidad.

\footnotetext{
${ }^{8}$ Para una exposición y reapropiación excelente de esta, así como del resto de las tesis vertidas por Benjamin en esta obra, remito a Mate, 2006, pp. 237-248.

${ }^{9}$ Un muy interesante y completo estudio sobre la importancia capital de la noción de Eingedenken dentro de la obra de Walter Benjamin, puede encontrarse en Palermo, 2012, pp. 103-130.
} 
Ahora bien, la condición de posibilidad para que este pasado, latente e inconcluso, pueda sobrepujar al presente, es la existencia de una afinidad, que el recuerdo moviliza, entre ambos momentos ${ }^{10}$. En los términos aquí propuestos, el sujeto puramente espiritualizado puede recordar su dimensión afectiva-pasional, debido a su semejanza con ella, pues "la consciencia es energía pulsional derivada, ella misma también impulso [...] si no existiese esa afinidad [...] tampoco existiría la idea de libertad" (Adorno, 2008, p. 246). Esta ligazón es la que permite romper la violencia mítica, y por tanto repetitiva, en la que se encuentra anclada el sujeto, ya que la formación actual "[d]el bloque cristalizado entre sujeto y objeto, [no es] de ningún modo ontológico sino histórico" (Adorno, 2003, p. 154).

Esta rememoración, precisamente, será la que de cauce a la autorreflexión del pensamiento, es decir, liberar a la racionalidad de su reducción instrumental, subrayando el sustrato material del cual emerge y que no se disipa en su devenir. El giro materialista de la filosofía, se alcanzará, precisamente, mediante el reconocimiento de la primacía del objeto, sin que ello opere en demérito de la mediación subjetiva en el dispositivo gnoseológico:

El primado del objeto es la intento obliqua de la intentio obliqua, no la intentio recta rediviva, es el correctivo de la reducción subjetiva, no la denegación de una participación subjetiva [...] Si se quiere, en cambio, alcanzar el objeto, no deben eliminarse sus determinaciones o cualidades subjetivas: ello contradiría, precisamente, la primacía del objeto. Si el sujeto tiene un núcleo de objeto, entonces las cualidades subjetivas del objeto constituyen, con mayor razón, un momento de lo objetivo. Pues únicamente como determinado se convierte el objeto en algo (Adorno, 2003, p. 148).

La posibilidad de esta experiencia no recortada del objeto, solo se logra alzando un coto a las pretensiones narcisistas del sujeto, es decir, a su carácter fundante y autodeterminado: "el sujeto tanto más es cuanto menos es, y tanto menos cuanto más se cree ser, cuanto más se ilusiona con ser algo para sí objetivo. Como momento, sin embargo, él es incancelable. Eliminado el momento subjetivo, el objeto se haría difuso, se desharía, al igual que los impulsos e instantes fugaces de la vida subjetiva" (156).

En virtud de lo expuesto se comprende que la crítica al sujeto apunta a su des-sustancialización, no para eliminarlo, sino para reconocer su mediación objetiva; pues, sólo con la reposición de su componente afectiva y somática, logrará desentrañar la verdad del objeto sin imponérsele: "la general aseveración de que las inervaciones, las intelecciones, el conocimiento son «solamente subjetivos», ya no surte efecto tan pronto la subjetividad es comprendida como figura de objeto [...] Es preciso retrotraer el sujeto mismo a su objetividad; no se trata de proscribir sus impulsos del conocimiento" (150).

\footnotetext{
${ }^{10}$ Para un abordaje de la relación entre mímesis y recuerdo, véase Abadi, 2013, pp.4-16.
} 
A través de este recuerdo de la naturaleza, en definitiva, se vehiculizan tanto la crítica epistemológica a la negación abstracta, así como la falsa separación entre sujeto y objeto:

El propósito de la Teoría Crítica adorniana no es la crítica de la razón, sino la crítica de la sociedad: se trata de mostrar cuánto hay de no-racional y de particularista en las formas de racionalidad socio-históricamente vigentes, sabiendo que para ello no cuenta con nada más que con la autorreflexión de la razón misma en su materialización histórica concreta. Por ello la insistencia de Adorno en lo no-idéntico y en el recuerdo de la naturaleza reprimida en el sujeto no responde al intento de poner estos elementos «a salvo» de la dinámica destructiva de la racionalidad instrumental, sino que más bien constituye la clave epistemológica desde la que plantea su crítica inmanente. Y es que la teoría adorniana es crítica en la medida en que se articula desde la «historia subterránea» de lo reprimido, deformado y mutilado en el proceso de civilización, tomando como punto de partida epistemológico los costes de dicho proceso en términos de renuncia, sufrimiento e injusticia. Y es que sólo desde el intento de hacer justicia a lo sofocado y reprimido por la razón dominante será posible dar lugar a un concepto no reducido de racionalidad (Maiso, 2010, p. 250).

Cabe notar que las afirmaciones presentadas podrían llevar a conclusiones apresuradas, que pretendan hacer de Adorno un realista ingenuo. Por ello, se considera necesario señalar que en su pensamiento no hay lugar para el hedonismo o el sensualismo remozado. Lo corporal no es una inmediatez cuya liberación permita acceder inmediatamente a una sociedad libre, puesto que "la naturaleza en sí no es buena. [...] Como modelo y meta, ella representa el antiespíritu, la mentira y la bestialidad; solo en la medida en que es conocida y reconocida como tal se convierte en el impulso de lo existente hacia su propia paz" (Adorno y Horkheimer, 2001, p. 299).

En contraste, la importancia de la rememoración de la naturaleza en el sujeto apunta a subrayar el sinsentido de los padecimientos ocurridos, trayendo a primera plana la verdad del proceso socializador al que es sometido el individuo, basado en la coacción y exclusión de su dimensión sensible. La conformación del sí mismo, el surgimiento de un yo autoconsciente, trae consigo la pérdida y destrucción del corazón mismo de la humanidad. Los requerimientos del sese conservare, la autoconservación spinoziana, entendida como la ley natural de todo ser, hace que el cuerpo viviente sea transformado en materia des-cualificada: "El cuerpo físico [Körper] no puede volver a transformarse en cuerpo viviente [Leib]. Sigue siendo un cadáver, por más que sea fortalecido. La transformación en cosa muerta, que se anuncia en su nombre, forma parte del proceso constante que ha reducido la naturaleza a material y a materia" (279). 
Esta descripción parecería no dejar espacio para el surgimiento efectivo de ese impulso somático, sede de la moralidad y libertad. Si la sociedad tardo capitalista existe como un sistema autosuficiente, donde lo general se incrusta en lo particular, haciendo que este lo reproduzca sin conflictos ni oposiciones, la esperanza de su modificación estaría aniquilada. Sin embargo, Adorno sostendrá que la radicalidad de la crítica a la categoría de sujeto encuentra su máximo potencial en el momento en que, gracias a la socialización plena del individuo, "la identidad de todo con todo se paga al precio de que nada puede ya ser idéntico consigo mismo" (67). Es la propia coacción desmedida de lo universal la que permite al particular, al individuo, erigirse como freno al proceso de alienación, ya que "la deshumanización es a la vez su contrario. La cosificación tiene sus límites en los seres humanos cosificados" (Adorno, 2004, p. 364). Esta declaración de principios encuentra su fundamento en la propia estructura libidinal de los hombres, que les impide ser reconducidos a meros portadores de funciones sociales, "pues en las necesidades mismas de los hombres aprehendidos y administrados, reacciona algo en lo que no están del todo aprehendidos, un excedente de participación subjetiva del que el sistema no se ha apoderado por completo" (Adorno, 2008, p. 95).

La diferencia entre ambos, individuo y sociedad, hace de la noción de espontaneidad, la zona de conflicto en la cual se dirime la integración funcional de los sujetos y el surgimiento de nuevas formas de resistencia y protesta: "lo social es una zona de contacto, la de la espontaneidad. La psicología no solo resulta relevante como medio de adaptación, sino también allí donde encuentra sus límites la socialización en el sujeto. Se opone a la vía social con fuerzas procedentes de ese estrato en el que el principium individuationis, mediante el que se impuso la civilización, se afirma aun contra el proceso de civilización que lo liquida" (Adorno, 2004, p. 85).

La referencia a este registro pulsional no tiene otra finalidad más que intervenir en el propio proceso cultural, desmintiendo sus cimientos y postulados "el psicoanálisis radical, al dirigirse a la libido como algo pre-social, alcanza filogenética y ontogenéticamente los puntos en los que el principio social de dominio coincide con el principio psicológico de la represión pulsional" (26). La dialectización de la enseñanza de Freud otorgará elementos valiosísimos en pos de trascender este mecanismo represivo; pues, el conflicto irresuelto entre las exigencias externas y las resistencias internas del sujeto constituye la contradicción fundamental que socava los cimientos mismos de la estructura social, ya que "como las renuncias cada vez mayores en la esfera de los instintos no encuentran equivalente en las compensaciones por las cuales el yo las acepta, los instintos reprimidos se rebelan. La socialización crea el potencial de su propia destrucción, no sólo en la esfera objetiva, sino también en la subjetiva" (Adorno y Horkheimer, 1969, p. 42). 
Para comprender cabalmente por qué Adorno sostendrá que en la esfera subjetiva se teje la posibilidad de trascender y modificar el estado de ofuscación actual, es necesario atender a la premisa según la cual "lo originado puede [...] ser superior a su origen" (Adorno, 2004, p. 84). De esta percepción se desprenden los fundamentos centrales de la crítica que Adorno somete a Freud. Según su postura, el padre del psicoanálisis, al afirmar que "el prójimo no es solamente un posible auxiliar y objeto sexual, sino una tentación para satisfacer en él la agresión, explotar su fuerza de trabajo sin resarcirlo, usarlo sexualmente sin su consentimiento, desposeerlo de su patrimonio, humillarlo, infligirle dolores, martirizarlo y asesinarlo" (Freud, 1992, p. 108) da una interpretación correcta de la relaciones vigentes entre los hombres, sin embargo, desacierta al suponer que "la inclinación agresiva es una disposición pulsional autónoma, originaria, del ser humano" (117). Según Freud existe una "hostilidad primaria y recíproca" (109) entre los hombres, basada en una "pulsión agresiva natural de los seres humanos" (118. Cursiva propia). La convicción de que aunque variase el modo de producción social, "ese rasgo indestructible de la naturaleza humana lo seguiría adonde fuese" (111), es interpretada por Adorno como una hipostatización de las determinaciones "actuales" del sujeto:

La teoría analítica denuncia la falta de libertad y la degradación de los seres humanos en la sociedad sin libertades [...] Pero, bajo su mirada médica conjurada con la muerte, la falta de libertad cuaja constituyéndose en invariante antropológica, y con ello el aparato conceptual cuasicientífico descuida en su objeto lo que no es sólo objeto: el potencial de la espontaneidad. Cuando más estrictamente se piensa el ámbito psicológico como campo de fuerzas autárquico, cerrado en sí mismo, tanto más completamente desubjetiviza la subjetividad. El alma arrojada sobre sí misma, por así decir, privada de objeto, se petrifica convirtiéndose en objeto (Adorno, 2004, p. 58).

El fundamento de tal confusión se debe a que hace del aparato psíquico un objeto de estudio autárquico, es decir, sin analizar detenidamente su anclaje material específico, volviendo, paradójicamente, a lo histórico en invariante y lo psicológico en variable:

No puede reprocharse a Freud que descuidara lo social concreto, sino que se conformara demasiado fácilmente con el origen social de ese carácter abstracto, con la rigidez del inconsciente que reconoce con la incorruptibilidad del científico. El empobrecimiento a través de la tradición sin fin de lo negativo, la hipostasión como una determinación antropológica. Lo histórico se torna así invariante, lo psíquico, por el contrario, se vuelve suceso histórico (57). 
De acuerdo con Adorno, es la internalización de la irracionalidad objetiva la que determina la irracionalidad del comportamiento del sujeto. La crueldad, antes que un rasgo natural y necesario de las relaciones interhumanas es producto de las renuncias que la sociedad impone al sujeto: "El impulso forzado a la crueldad y a la destrucción surge de la represión orgánica de la proximidad respecto al cuerpo" (Adorno y Horkheimer, 2001, p. 278. Cursiva propia ${ }^{11}$ ).

La agresividad se manifiesta, bajo esta óptica, como el reverso necesario de la reificación del cuerpo, como una respuesta frente a la mediación históricamente determinada del modo en que deben ser tramitadas las exigencias pulsionales. Esta no es más que la consecuencia de volver al cuerpo una mercancía que sólo logra expresarse a través del síntoma:

Pero el asesino, el sicario, los gigantes embrutecidos, que son utilizados secretamente como verdugos por los poderosos, legales e ilegales, grandes y pequeños [...] el odio-amor hacia el cuerpo es brutal e inmediato; ellos violan todo lo que tocan, destruyen lo que ven a la luz, y esta destrucción es el rencor por la reificación; todos ellos repiten con ciego furor sobre el objeto viviente lo que no pueden impedir que haya acontecido: la escisión de la vida en espíritu y en su objeto. El hombre los atrae irresistiblemente; quieren reducirlo al cuerpo; nada debe tener derecho a vivir (279).

Dentro del armazón teórico adorniano, la crueldad y la agresividad, no responden a una inclinación natural del hombre, sino que son producto del llamado mecanismo de falsa proyección, expuesto en Dialéctica de la llustración, el cual se alimenta de ese resabido mimético originario del hombre, invirtiendo su finalidad: el impulso de dejarse llevar, trueca en la violencia y agresión contra lo débil y sometido:

Esta [la falsa proyección] es lo opuesto a la verdadera mímesis, pero es profundamente afín a la mímesis reprimida: quizás, incluso, el rasgo morboso en el que ésta cristaliza. Si la mímesis se asimila al ambiente, al mundo circundante, la falsa proyección asimila, en cambio, el ambiente a sí misma. Si para aquélla lo externo se convierte en el modelo al que lo interno se adecúa y lo extraño se vuelve familiar, la falsa proyección transpone lo interno, a punto de estallar, en lo externo y configura incluso lo más familiar como enemigo. Los impulsos que el sujeto no deja pasar como suyos, y que sin embargo le pertenecen, son atribuidos al objeto, a la víctima potencial [...] Los mismos impulsos sexuales que el género humano ha reprimido supieron conservarse y afirmarse - tanto en los individuos aislados como en pueblos enteros- en la transformación imaginaria del mundo ambiente en un sistema diabólico (230-231).

\footnotetext{
${ }^{11}$ Nótese que el motivo de los destacados de las citas de Freud y Adorno, es el de señalar que, para el primero, es natural la tendencia a la agresividad, mientras que para el segundo, forzada.
} 
Si Freud ha señalado en Psicología de las masas y análisis del yo que "en la vida anímica del individuo, el otro cuenta, con total regularidad, como modelo, como objeto, como auxiliar y como enemigo, y por eso desde el comienzo mismo la psicología individual es simultáneamente psicología social" (Freud, 1992b, p. 67), se comprende que el mecanismo de falsa proyección, el delirio paranoico y la agresividad, en tanto núcleos articuladores de las relaciones humanas, forman, en realidad, las estrategias de adaptación de una pseudo-individualidad narcisista, como puede comprenderse a partir de las siguientes líneas: "narcisismo dentro del psicoanálisis quiere decir: catexia libidinosa del propio yo en lugar del amor a otros seres humanos. El mecanismo de este desplazamiento no es en último extremo sino el mecanismo social que premia el endurecimiento de cada individuo, la desnuda voluntad de autoconservación" (Adorno, 2004, p. 408).

El imperio de la autoconservación conlleva, necesariamente, la reducción de toda realidad material a un mero objeto de sometimiento, siendo el sujeto incapaz de realizar "ninguna catexis positiva" (Adorno, 2008b, p.480). Como producto de esta fijación de la libido en el propio yo, se constituye un sí mismo abstracto y alienado, frente a un mundo igualmente cosificado: "en la constitución vigente de la existencia, las relaciones entre los hombres surge ni de su libre voluntad ni de sus pulsiones, sino a partir de leyes sociales y económicas que se imponen sobre sus cabezas" (Adorno, 2004, p. 34).

Tomando como horizonte de sentido el hecho de que "toda pulsión está tan socialmente mediada que su componente natural no aparece nunca de forma inmediata, sino siempre como algo producido por lo sociedad" (365), Adorno sostendrá que un cambio en las relaciones materiales de existencia repercutirá en la estructura psíquica del sujeto, puesto que "la afloración concreta de las pulsiones puede experimentar en grandísima medida variaciones y modificaciones dinámicas" (21) a lo largo de la historia.

Según lo anterior, se desprende que la afirmación realizada por el pensador frankfurtiano, a saber, "el potencial del psicoanálisis es el del desencadenamiento de la pulsión" (34), es una apuesta que busca liberar y desanudar a la actividad pulsional de aquella fijación que la pone al servicio de los mandatos de la autoconservación del statu quo. Una relación modificada en la constitución interna del individuo, entre la res cogita y la res extensa, por fuera del sometimiento de esta por aquella, permitirá desmentir el carácter invariable de los instintos y las necesidades humanas (tanto materiales como psicológicas). Estas no están colonizadas, sino producidas por las exigencias del desarrollo capitalista; por ello, no se buscará encontrar en esta "naturalidad" la sustancia no pervertida de la humanidad, sino conmover su trabazón con la ideología dominante, encontrar una mediación diferenciada entre sociedad y naturaleza donde ambas se potencien: "cuando la producción se reoriente en el acto, sin condiciones ni límites, a la satisfacción de las necesidades, también y precisamente de las producidas por el capitalismo, se trasformarán con ello de forma decisiva las necesidades mismas" (367). 


\section{La felicidad como redención: moralidad e intersubjetividad}

Para recapitular, se puede afirmar que, en definitiva, Adorno propone un doble aspecto de la noción de no identidad que permita dar cauce a la dimensión expresiva y normativa del hombre. La primera hace referencia al reconocimiento de "lo no subjetivo en el sujeto" (Adorno, 2004b, p. 195), resaltando la imposibilidad de volverlo un compartimento igual e idéntico a sí mismo: "la expresión busca lo transubjetivo, la figura del conocimiento que, habiendo precedido en tiempos a la polaridad de sujeto y objeto, no la reconoce como algo definitivo" (193). La expresión, por tanto, pretende dar voz al sustrato material, sensible y pulsional del individuo. A su vez, la perspectiva normativa, vehiculiza la diferencia existente entre el particular y la sociedad, ya que si bien este es producto de la totalidad imperante, no se reduce a ella, por el contrario, es "el único potencial, mediante el cual puede transformarse esta sociedad. En él se acumula toda la negatividad del sistema, pero, al mismo tiempo, también aquello que va más allá del sistema tal como es en este momento" (Adorno, 1996, p. 199).

El señalamiento de esta doble no identidad (del sujeto consigo mismo y con respecto a la sociedad) será, precisamente, la cuña que desmiente la moralidad como el receptáculo de una subjetividad autónoma y espiritualizada. Con ello, lo que se busca es romper la cárcel del sujeto por su propia fuerza: "la mera subjetividad que se empeña en la pureza de su propio principio se enreda en antinomias [...] La moral, la autonomía basada en la pura certeza de sí mismo y hasta la conciencia moral son mera apariencia" (Adorno, 2003, p. 248).

El reposicionamiento de la moral por fuera de la egoidad absoluta implica el reconocimiento de la prioridad del objeto también en este ámbito: "la primacía del objeto debe ser respetada por la praxis; la crítica del idealista Hegel a la ética kantiana de la conciencia moral hizo notar esto por primera vez. Solo se comprende bien la praxis, si el sujeto, por su parte, es algo mediado, a saber: si es aquello que quiere al objeto; la praxis responde al estado carencial del sujeto" (166).

La vinculación materialista entre moral y praxis, por tanto, requiere que el sujeto piense la determinación efectiva de su relación con la otredad: "no nos hacemos hombres libres a medida que nos realizamos a nosotros mismos [...] como individuos, sino en la medida en que salirnos fuera de nosotros mismos, vamos al encuentro de los demás y, en cierto sentido, nos entregamos a ellos" (137). 
De este modo, toda práctica intersubjetiva ya no es producto de una legislación formal despojada del campo de las inclinaciones, lo afectivo, pulsional y pasional; por el contrario, es una relación sujeto-objeto modificada con base en la actualización de dichas dimensiones, permite sentar los fundamentos de una interacción no violenta entre los hombres:

Lo que más tarde se llama subjetividad, liberándose del miedo ciego del estremecimiento, es al mismo tiempo su propio despliegue; no es vida en el sujeto nada más que el estremecimiento, la reacción al hechizo total que lo trasciende. La consciencia sin estremecimiento es la consciencia cosificada. El estremecimiento en que la subjetividad se agita sin ser todavía es el hecho de estar impresionado por lo otro [...] se amolda a ese estremecimiento en vez de someterlo (Adorno, 2004b, p. 406).

Según la perspectiva de Adorno, la verdadera praxis, hará de la dimensión mimética del hombre la sede de todo comportamiento libre: "la autenticidad no es otra cosa que el obstinado y altanero encastillarse en la forma monadológica que la opresión social imprime al hombre. Lo que no quiere marchitarse prefiere llevar el estigma de lo inauténtico. Entonces vive de la herencia mimética. Lo humano se aferra a la imitación: un hombre se hace verdaderamente hombre sólo cuando imita a otros hombres" (Adorno, 1999, p. 154).

Asimismo, esta praxis permite trascender la lógica de la producción y el intercambio, condición necesaria para la organización de una sociedad libre; al tiempo que posibilita la superación del sistema capitalista y las coacciones sobre las que se apoya, permitirá no solo abolir la explotación y la desigualdad, sino también establecer una relación no destructiva con la naturaleza, así como evitar un desarrollo anárquico de las fuerzas productivas, suprimiendo con ello el carácter alienante del trabajo: "bajo la presión de la sociedad, sólo la ingeniosa combinación de trabajo y felicidad puede aún dejar abierto el camino a la auténtica experiencia" (130).

La consecuencia más obscena de la situación actual radica en el hecho de que, si bien las potencialidades desarrolladas por el sistema capitalista permitirían abolir el hambre, el afán de lucro que lo moviliza lo impide y condena a millones de personas a la miseria extrema. Por esta razón, la superación de esta situación anida en el corazón mismo del materialismo adorniano:

El punto de fuga del materialismo histórico sería su propia superación, la liberación del espíritu con respecto a la primacía de las necesidades materiales en el estado de su satisfacción. Sólo con el impulso corporal aplacado se reconciliaría el espíritu y se convertiría en lo que no hace sino prometer desde hace tanto tiempo como bajo la sujeción a las condiciones materiales niega la satisfacción de las necesidades materiales (Adorno, 2008, p. 195). 
En virtud de esta declaración propositiva, se entiende que la categoría de felicidad opere, por su ausencia, como índice de una sociedad emancipada: "toda felicidad hasta el día de hoy promete lo que todavía no ha sido" (324). Si bien, como se deprende de lo antedicho, la felicidad "aspira a la consumación sensible y en ésta obtiene su objetividad" (191), dicho concepto no remite únicamente al mero aplacamiento del impulso somático, sino que apunta a percibir en las condiciones materiales y concretas de existencia, las determinaciones que han de ser modificadas para conseguir un ordenamiento más justo, lo cual no implica la realización de una sociedad transparente, sin ningún tipo de conflictos, sino que estos sean, ahora, los propios de un sujeto no cosificado, es decir, verdaderamente humano.

Si, como se ha dicho, el corpus adorniano opera en pos de conmover el paradigma del cuerpo-patológico, señalando la posibilidad de erigir a este como fuente de resistencia frente a las calamidades reinantes, es necesario, para completar este proyecto, introducir la problemática de la felicidad ${ }^{12}$ como parte de una corporalidad que opere por fuera de la representación del sí mismo: "no hay felicidad más que cuando el sí-mismo no es él mismo [...] La utopía sería la no-identidad, sin sacrificio, del sujeto" (259). Como sostiene Adorno, la emergencia de un sujeto cualitativo y diferenciado está inherentemente ligado a la transformación del cuerpo: "La no-verdad ideológica en la concepción de la trascendencia es la separación de cuerpo y alma, reflejo de la división del trabajo. Llega a la idolatración de la res cogitans como el principio dominador de la naturaleza y a una negación material, que se desharía en el concepto de una trascendencia más allá del contexto de culpa. Pero la esperanza va unida, como en la canción de Mignon, al cuerpo transfigurado" (366).

Formando una constelación dialéctica con la noción de no identidad, la cual moviliza el carácter normativo y expresivo del sujeto, el concepto de felicidad se torna una categoría ligada a la problemática de la salvación del particular. Puesto que, "la felicidad sólo sería la redención de la particularidad en cuanto principio universal" (324), se comprende que se erija en el vértice de una crítica materialista, tanto epistemológica como social, a la vez que constituya el elemento articulador del proyecto ético adorniano. En lo que atañe a la cuestión epistemológica, la temática de la felicidad interviene en la dialéctica sujeto-objeto, para resquebrajar el principio de identidad, permitiendo la libre expresión de las múltiples determinaciones de la cosa: "lo que simplemente es idéntico a sí mismo carece de felicidad" (Adorno, 2009, p. 473). Dado que, la "crítica del conocimiento es crítica de la sociedad y viceversa" (Adorno, 2003, p.149), se comprende que el cuestionamiento al concepto de identidad, emparentado originariamente con el

\footnotetext{
12 Respecto a la cuestión de la felicidad dentro de la obra de Adorno, si bien no es coincidente punto por punto con la lectura aquí realizada, resulta muy esclarecedora e interesante la propuesta contenida en Schwarzböck, 2008, pp. 23-97.
} 
intercambio de equivalentes, impactará de lleno en la especificidad de la matriz de acumulación vigente. Frente a este, la felicidad, posicionándose más allá de la reducción instrumental, que torna a todos los elementos existentes en recíprocos e iguales, no está "sujeta a intercambio, ni tampoco es demandable [...] La felicidad está anticuada: es ineconómica” (Adorno, 1999, pp. 218-219), de ahí que proponga modos de organización social que no hagan de la producción por mor de la producción, "fachada universal de una praxis falsa" (Adorno, 2008, p. 357) el factor que regule su devenir. Por último, su posicionamiento normativo constituye un sucedáneo de las cuestiones anteriormente vertidas, ya que, al contrariar la abstracción producida por el principio de identidad, se habilita el surgimiento de nuevas formas de estructuración comunitaria, donde la interacción entre los hombres y con su medio, logre desenvolverse ajeno a la violencia y dominación, propias de las sostenidas por un yo encorsetado en sí mismo: "La situación reconciliada no anexaría lo ajeno al imperialismo filosófico, sino que tendría su felicidad en que lo lejano y distinto permanezca en la cercanía otorgada, más allá tanto de lo heterogéneo como de lo propio" (181).

De esta manera, inocular la dimensión de y la pregunta por la felicidad en todo proyecto crítico supone ir más allá del posicionamiento que hace de la esfera social de la economía al modificarla para alcanzar una reconciliación entre lo universal y lo particular. Así, en tanto categoría crítica, apunta a interrogarse por la forma de vida correcta y plena, donde los individuos maximicen su bienestar por fuera del interés meramente individual: "En suma, cualquier cosa que se pueda llamar moralidad hoy, emerge dentro de la pregunta por la organización del mundo. Se puede decir que la pregunta por lo que sería una vida justa es la pregunta por la forma política justa" (Adorno, 2000, p. 176. Traducción propia).

Si bien es extensamente conocida su reticencia a positivizar el contenido de una sociedad justa en todas sus dimensiones, esto no impide reconocer que las respuestas a las exigencias surgidas de la dimensión somática, afectiva o pulsional de la humanidad constituirán su eje central: "Semejante organización tendría su telos en la negación del sufrimiento físico aun del último de sus miembros y de las formas interiores de reflexión de ese sufrimiento. Tal es el interés de todos, únicamente realizable poco a poco mediante una solidaridad transparente a sí misma y a todo viviente" (Adorno, 2008, p. 192) $\Phi$

\section{REFERENCIAS}

Abadi, F. (2013). "Mímesis y rememoración en Walter Benjamin". Aporía. Revista Internacional de Investigaciones Filosóficas. Número (6). pp. 4-16.

Adorno, T. (1996). Introducción a la sociología. Barcelona: Grijalbo. 
Adorno, T. (1999). Mínima Moralia. Madrid: Taurus.

Adorno, T. (2000). Problems of Moral Philosophy. Cambridge: Polity Press.

Adorno, T. (2003). Consignas. Buenos Aires: Amorrortu.

Adorno, T. (2004). Escritos sociológicos I. Madrid: Akal.

Adorno, T. (2004b). Teoría Estética. Madrid: Akal.

Adorno, T. (2008). Dialéctica Negativa. La jerga de la autenticidad. Madrid: Akal.

Adorno, T. (2008b). Escritos sociológicos II. Madrid: Akal.

Adorno, T. (2009). Crítica de la cultura y sociedad, Vol. II. Madrid: Akal.

Adorno T. y Horkheimer, M. (1969). La sociedad. Lecciones de sociología. Buenos Aires: Proteo.

Adorno, T. y Benjamin, W. (1998). Correspondencia (1928-1940). Madrid: Trotta.

Adorno, T. y Horkheimer, M. (2001). Dialéctica de la llustración. Madrid: Trotta.

Bernstein, J. (2001). Adorno: Disenchantment and Ethics. Cambridge: Cambridge University Press.

Cabot, M. (1997). El penós camí de la raó: Theodor W. Adorno i la crítica de la modernitat. Palma: Universitat de les Illes Balears.

Cook, D. (2011). Adorno on nature. New York: Routledge.

Foster, R. (2007). Adorno: The Recovery of Experience. Albany State: University of New York.

Foucault, M. (1996). La vida de los hombres infames. Buenos Aires: Altamira.

Freud, S. (1982). Obras completas. Vol. XIX. Buenos Aires: Amorrortu.

Freud, S. (1990). Obras completas. Vol. XII. Buenos Aires: Amorrortu.

Freud, S. (1992). Obras completas. Vol. XXI. Buenos Aires: Amorrortu.

Freud, S. (1992b). Obras completas. Vol. XVIII. Buenos Aires: Amorrortu. 


\section{Das volle subjekt. Dominación, moralidad y libertad en el pensamiento de T. W. Adorno}

Gómez, V. (1998). El pensamiento estético de Theodor W. Adorno. Valencia: Fronesis.

Gagnebin, J.M. (1993). "Do conceito de mímesis no pensamento de Adorno e Benjamin". Perspectivas. Revista de Ciencia Sociales. Número (16). pp. 67-86.

Jameson, F. (2010). Marxismo tardío. Adorno y la persistencia de la dialéctica. Buenos Aires: Fondo de Cultura Económica.

Jarvis, S. (1998). Adorno: A Critical Introduction. Cambridge, UK: Polity Press.

Jay, M. (1997). "Mimesis and mimetology: Adorno and Lacoue-Labarthe". En T. Huhn, and Z. Lambert (eds.). The Semblance of Subjectivity. Cambridge, Mass.: The MIT Press.

Kant, I. (1951). Crítica de la razón práctica. Buenos Aires: El Ateneo.

Laplanche, J. y Pontalis, J. (2004). Diccionario de psicoanálisis. Buenos Aires: Paidós.

Maiso, J. (2010). Elementos para la reapropiación de la teoría crítica de Theodor W. Adorno. Salamanca: Ediciones de la Universidad de Salamanca.

Maiso, J. (2012). "Remembrance of Nature Within the Subject. Critical Theory, Psychoanalysis and the Limits of Subjection". En A. Martinengo (ed.). Beyond Deconstruction: From Hermeneutics to Reconstruction. Boston: De Gruyter.

Maiso, J. (2013). "Subjetividad dañada. Teoría Crítica y psicoanálisis". Constelaciones. Revista de Teoría Crítica. Volumen 5. pp. 132-150.

Marx, K. (2009). El capital. TI. Buenos Aires: Siglo XXI.

Mate, R. (2006). Medianoche en la historia. Madrid: Trotta.

O'Connor, B. (2004). Adorno's Negative Dialectic. Cambridge, Mass.: MIT Press.

Palermo, S. (2012). "El hilo sutil de la rememoración. Felicidad y redención histórica en la obra de Walter Benjamin". Revista de Filosofía y Teoría Política. Número (43). pp. 103-130.

Tafalla, M. (2003). Adorno. Una filosofía de la memoria. Barcelona: Herder.

Schwarzbock, S. (2008). Adorno y lo político. Buenos Aires: Prometeo. 
Schweppenhäuser, G. (2003). "A filosofía moral negativa de Theodor W. Adorno". Educação \& Sociedade. Volumen 24 (83). pp. 391-415.

Zamora, J. (2004). Th. W. Adorno. Pensar contra la barbarie. Madrid: Trotta.

Zamora, J. (2007). "El enigma de la docilidad: Teoría de la sociedad y psicoanálisis en Th. W. Adorno". En M. Cabot (ed.). El pensamiento de Th. W. Adorno. Balance y perspectivas. Palma de Mallorca: Universitat de les Illes Balears.

Zuidervaart, L. (2007). Social Philosophy after Adorno. Cambridge: Cambridge University Press. 